\title{
Tie-Lines and Mixing Properties of Solid Solutions in the System CaO-SrO-PbO-O at $1100 \mathrm{~K}$
}

\author{
K.T. Jacob and K.P. Jayadevan
}

(Submitted 7 December 1999; in revised form 9 May 2000)

\begin{abstract}
Phase relations in the system $\mathrm{CaO}-\mathrm{SrO}-\mathrm{PbO}-\mathrm{O}_{2}$ at $1100 \mathrm{~K}$ have been determined by equilibrating samples with different compositions in air, oxygen, or evacuated ampoules for 7 days and characterizing quenched specimens by optical and scanning electron microscopy, energy-dispersive analysis of $x$-rays (EDX), and $x$-ray diffraction (XRD). There is a solid-state miscibility gap in the pseudo-binary system CaO-SrO, and continuous solid solubility between $\mathrm{Ca}_{2} \mathrm{PbO}_{4}$ and $\mathrm{Sr}_{2} \mathrm{PbO}_{4}$ at $1100 \mathrm{~K}$. Substitution of Ca for $\mathrm{Sr}$ occurs only to a limited extent $\left(\sim 2\right.$ mol.\%) in $\mathrm{SrPbO}_{3}$. The calcium-rich solid solutions $\left(\mathrm{Ca}_{1-y} \mathrm{Sr}_{y}\right)_{2} \mathrm{PbO}_{4}$ characterized by $y \leq 0.255$ are in equilibrium with $\mathrm{PbO}$ in air; compositions with $y \geq 0.255$ coexist with $\left(\mathrm{Ca}_{1-z} \mathrm{Sr}_{z}\right) \mathrm{PbO}_{3}$. There is a three-phase region involving the two monoxide solid solutions $\left(\mathrm{Ca}_{1-x} \mathrm{Sr}_{x}\right) \mathrm{O}$ on either side of the miscibility gap with $x=0.24$ and 0.71 and $\left(\mathrm{Ca}_{1-y} \mathrm{Sr}_{y}\right)_{2} \mathrm{PbO}_{4}$ with $y=0.96$. Accurately determined are the locations of tie-lines between the solid solutions. Attainment of equilibrium was checked by the conventional tie-line rotation technique. The excess Gibbs energy of mixing of the solid solution with orthorhombic structure is obtained by an analysis of tie-line data; for the mixing of one mole of $\mathrm{Ca}$ and $\mathrm{Sr}$ represented by $\left(\mathrm{Ca}_{1-y} \mathrm{Sr}_{y}\right) \mathrm{Pb}_{0.5} \mathrm{O}_{2}, \Delta G^{E}=y(1-y)[15,840-2950 y] \mathrm{J} / \mathrm{mol}$. The thermodynamic properties suggest the onset of immiscibility in this solid solution below 884 $( \pm 5) \mathrm{K}$. The miscibility gap is asymmetric with a critical composition at $y=0.43( \pm 0.02)$. Inside the triangle $\left(\mathrm{Ca}_{1-y} \mathrm{Sr}_{y}\right) \mathrm{Pb}_{0.5} \mathrm{O}_{2}-\left(\mathrm{Ca}_{1-z} \mathrm{Sr}_{z}\right) \mathrm{PbO}_{3}-\mathrm{PbO}$, a small liquid-phase region is present close to the $\mathrm{PbO}$ corner, surrounded by three two-phase fields. Each corner of the approximately triangular liquid-phase region is associated with a three-phase field.
\end{abstract}

\section{Introduction}

The solid solution $\left(\mathrm{Ca}_{1-y} \mathrm{Sr}_{y}\right)_{2} \mathrm{PbO}_{4}$ with orthorhombic structure is formed during the synthesis and processing of superconducting phases belonging to the system $\mathrm{Bi}(\mathrm{Pb})-\mathrm{Sr}-$ $\mathrm{Ca}-\mathrm{Cu}-\mathrm{O} .^{[1]}$ The presence of $\mathrm{PbO}$ is known to enhance the superconducting phase formation. It alters the sequence of steps in compound formation from precursors. The reaction of $\mathrm{PbO}$ and $\mathrm{SrCO}_{3}$ starts at $\sim 1000 \mathrm{~K}$ with the formation of $\mathrm{PbSrO}_{3}$. The formation of $\mathrm{Sr}_{2} \mathrm{PbO}_{4}$ is observed only above $1223 \mathrm{~K}$. Knowledge of phase relations is necessary for precise control and optimization of high-temperature chemical processing routes.

As part of systematic studies on phase relations and thermodynamic properties of systems of interest to oxide superconductors, ${ }^{[2-14]}$ the system $\mathrm{CaO}-\mathrm{SrO}-\mathrm{PbO}-\mathrm{O}_{2}$ was investigated at $1100 \mathrm{~K}$. Xu et al. ${ }^{[15]}$ have reported on the synthesis and characteristics of the solid solution $\left(\mathrm{Ca}_{1-y} \mathrm{Sr}_{y}\right)_{2} \mathrm{PbO}_{4}$ belonging to this system. Isothermal sections of the phase diagram for the system $\mathrm{CaO}-\mathrm{SrO}-\mathrm{PbO}$ in air from 973 to $1123 \mathrm{~K}$ were reported by Kitaguchi et al. ${ }^{[16]}$ and Wong-Ng et $a{ }^{[17]}$ There are some differences in the results reported by these investigators. Moreover, the ternary oxides $\left(\mathrm{M}_{2} \mathrm{PbO}_{4}\right.$ and $\mathrm{MPbO}_{3}$ ) identified in the system do not belong to the pseudoternary system $\mathrm{CaO}-\mathrm{SrO}-\mathrm{PbO}$. They contain excess

K.T. Jacob and K.P. Jayadevan, Materials Research Center and Department of Metallurgy, Indian Institute of Science, Bangalore 560 012, India. Contact e-mail: katob@metalrg.iisc.ernet.in oxygen since lead is present in the tetravalent state. The reported isothermal sections can at best be considered as a projection of phase relations in the quaternary system $\mathrm{CaO}$ $\mathrm{SrO}-\mathrm{PbO}-\mathrm{O}_{2}$ from the oxygen apex to the ternary triangle $\mathrm{CaO}-\mathrm{SrO}-\mathrm{PbO}$. Thermodynamic information on the ternary solid solution phases is not available in the literature. The purpose of this study is to obtain quantitative information on phase relations and derive thermodynamic properties of solid solutions from the analysis of tie-line data. There are serious experimental restrictions on direct thermodynamic measurements on the solid solutions.

\section{Experimental Procedure}

\section{Materials}

The starting materials were lead monoxide $(\mathrm{PbO})$, calcium carbonate $\left(\mathrm{CaCO}_{3}\right)$, and strontium carbonate $\left(\mathrm{SrCO}_{3}\right)$ with nominal purity greater than $99.99 \%$. The monoxides $\mathrm{CaO}$ and $\mathrm{SrO}$ were prepared by thermal decomposition of their carbonates in vacuum at $1073 \mathrm{~K}$. The monoxide solid solutions $\left(\mathrm{Ca}_{1-x} \mathrm{Sr}_{x}\right) \mathrm{O}$ were prepared by ball milling appropriate mixtures of carbonates for $2 \mathrm{~h}$ and then decomposing the mixed carbonate under vacuum at $1073 \mathrm{~K}$. Platinum crucibles were used to contain the carbonates. The resulting oxide mixtures were compacted into pellets using a steel die in an inert-gas glove box. The pellets were heat treated in a flowing inert-gas atmosphere at a temperature of $1573 \mathrm{~K}$ for 3 days 


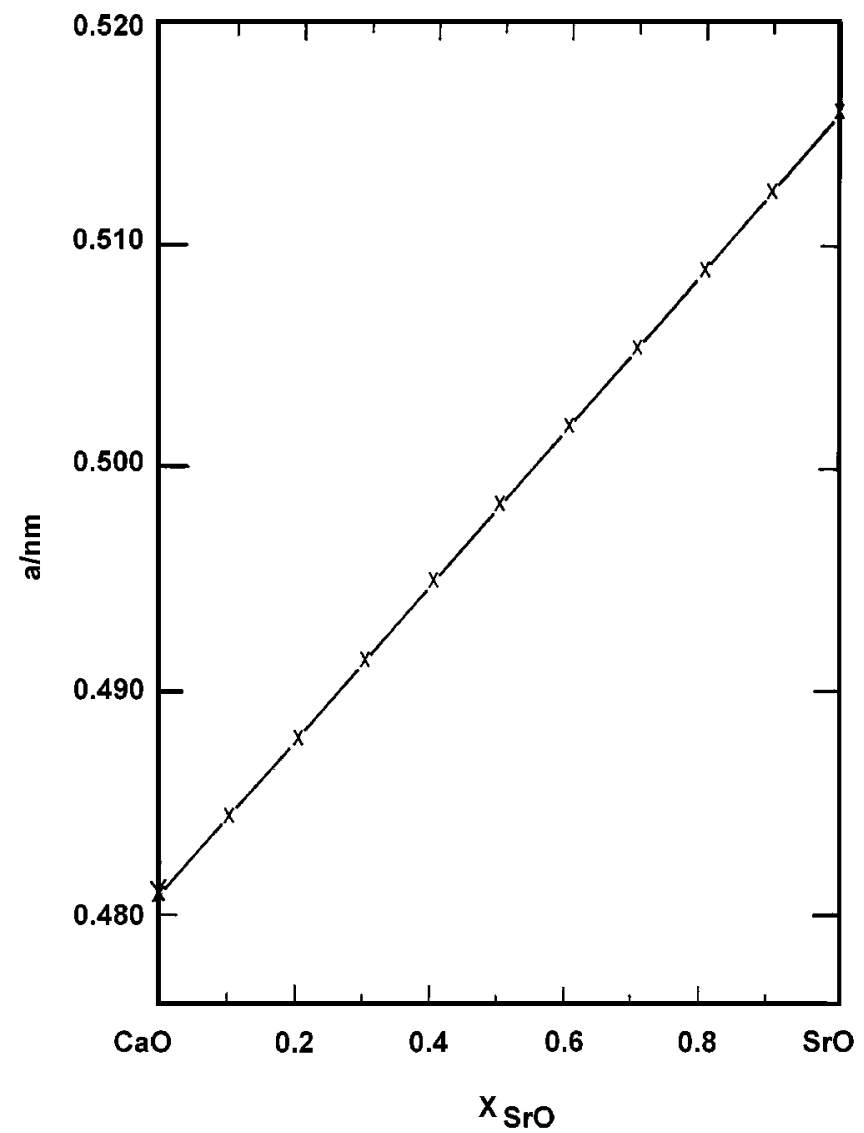

Fig. 1 Variation of the lattice parameter of the monoxide solid solution, having the rock-salt structure, with composition

and rapidly cooled to room temperature. Powder x-ray diffraction (XRD) confirmed the formation of solid solutions. The samples were kept in a closed sample holder during $\mathrm{X}$ ray analysis. The lattice parameters were refined using the Rietveld procedure. The variation of the lattice parameter of the monoxide solid solution with composition is shown in Fig. 1.

The compounds $\mathrm{Ca}_{2} \mathrm{PbO}_{4}$ and $\mathrm{Sr}_{2} \mathrm{PbO}_{4}$ were made by pelletizing an intimate mixture of component oxides $\mathrm{MO}$ $(\mathrm{M}=\mathrm{Ca}, \mathrm{Sr})$ and $\mathrm{PbO}$ and heating the pellets in air for $\sim 2$ days. Each pellet was crushed and repelletized twice during this period. The temperature of synthesis was 1073 $\mathrm{K}$ for $\mathrm{Ca}_{2} \mathrm{PbO}_{4}$ and $1273 \mathrm{~K}$ for $\mathrm{Sr}_{2} \mathrm{PbO}_{4}$. The solid solution $\left(\mathrm{Ca}_{1-y} \mathrm{Sr}_{y}\right)_{2} \mathrm{PbO}_{4}$ was prepared from the end members, $\mathrm{Ca}_{2} \mathrm{PbO}_{4}$ and $\mathrm{Sr}_{2} \mathrm{PbO}_{4}$, by heating mixtures in the appropriate ratio at $1100 \mathrm{~K}$. Identification of ternary compounds was made by XRD. The inductively coupled plasma emission technique and energy dispersive analysis of X-rays (EDX) confirmed the composition of the solid solutions. Lattice parameters of the solid solution $\left(\mathrm{Ca}_{1-y} \mathrm{Sr}_{y}\right)_{2} \mathrm{PbO}_{4}$ are plotted as a function of composition in Fig. 2. The variation is linear in conformity with Vegard's law. Kitaguchi et al. ${ }^{[16]}$ reported small positive deviations from Vegard's law. Xu et al. ${ }^{[15]}$ and Wong-Ng et al. ${ }^{[17]}$ observed almost linear dependence of the lattice parameters on composition, although the limited number of samples and scatter in their data do not permit any definite conclusions to be drawn. Figure 1 and 2 were

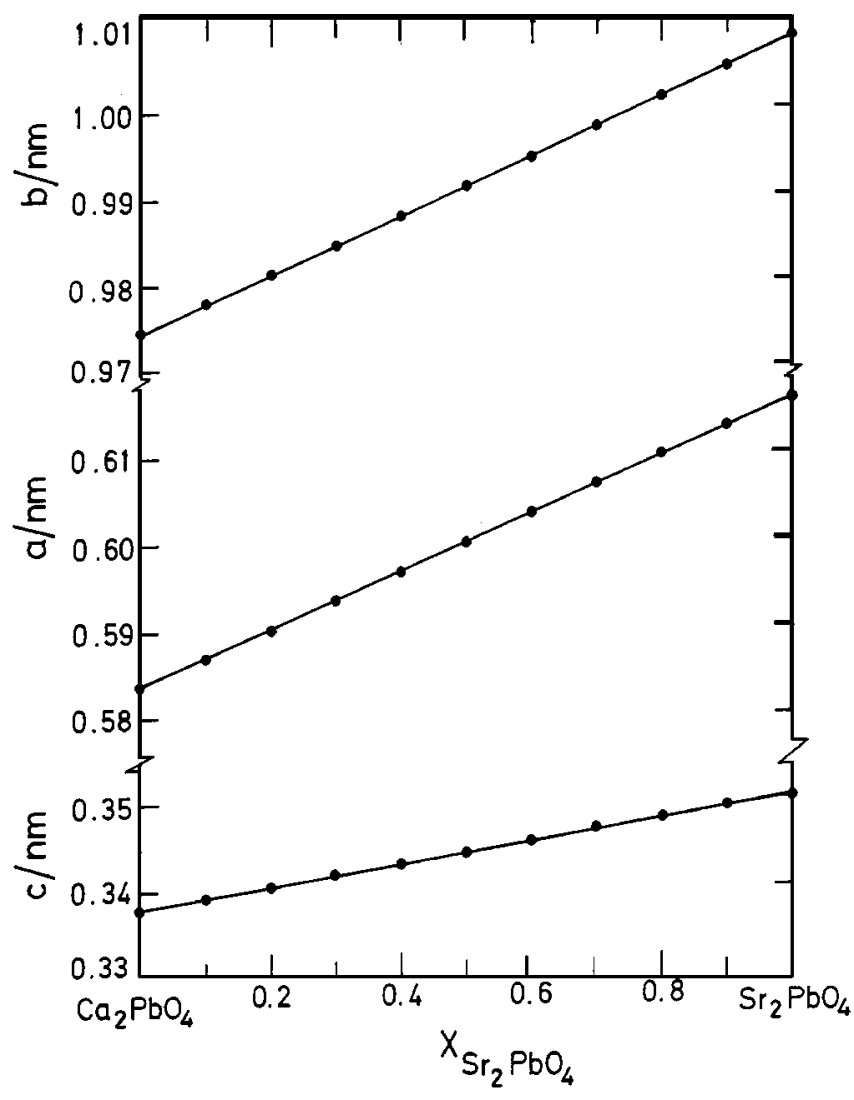

Fig. 2 Variation of the lattice parameters of the solid solution $\left(\mathrm{Ca}_{1-y} \mathrm{Sr}_{y}\right)_{2} \mathrm{PbO}_{4}$, crystallizing in the orthorhombic structure, with composition

used as calibration curves to derive unknown compositions of the solid solution phases in equilibrated samples from their measured lattice parameters. The unit cell dimensions increase as $\mathrm{Sr}^{2+}$ is substituted for $\mathrm{Ca}^{2+}$ ions in both series of solid solutions.

Attempts to make $\mathrm{CaPbO}_{3}$ by heating an equimolar mixture of $\mathrm{CaO}$ and $\mathrm{PbO}$ in air were not successful. The product always consisted of a mixture of $\mathrm{PbO}$ and $\mathrm{Ca}_{2} \mathrm{PbO}_{4}$. The compound $\mathrm{SrPbO}_{3}$ was made by heating an equimolar mixture of $\mathrm{SrO}$ and $\mathrm{PbO}$ in air at $1123 \mathrm{~K}$. Attempts to synthesize the compound $\mathrm{Ca}_{2} \mathrm{PbO}_{3}$ by heating a mixture of $\mathrm{CaO}$ and $\mathrm{PbO}$ at $1073 \mathrm{~K}$ in evacuated quartz ampoules and under argon gas were unsuccessful.

Argon and helium gases of $99.999 \%$ purity, used as the inert atmosphere, were passed over sodium hydroxide $(\mathrm{NaOH})$ to remove trace carbon dioxide $\left(\mathrm{CO}_{2}\right)$ and over anhydrous magnesium perchlorate $\left(\mathrm{Mg}\left(\mathrm{ClO}_{4}\right)_{2}\right)$ and phosphorus pentoxide $\left(\mathrm{P}_{2} \mathrm{O}_{5}\right)$ to remove trace water vapor $\left(\mathrm{H}_{2} \mathrm{O}\right)$. The inert gases were then deoxidized by passing them through columns of copper wool at a temperature of $723 \mathrm{~K}$ and titanium granules at $1150 \mathrm{~K}$.

The oxygen gas used in this study was $99.999 \%$ pure. Air was dried by passing through granular absorbents, compressed, and stored in a cylinder. Both air and oxygen were passed through $\mathrm{CuO}$ at $700 \mathrm{~K}$ to oxidize residual $\mathrm{CO}$ to $\mathrm{CO}_{2}$ and $\mathrm{H}_{2}$ to $\mathrm{H}_{2} \mathrm{O}$. The trace amount of $\mathrm{CO}_{2}$ in the gas was then absorbed by $\mathrm{NaOH}$. The residual $\mathrm{H}_{2} \mathrm{O}$ was removed by 
passage through columns containing silica gel and anhydrous $\mathrm{Mg}\left(\mathrm{ClO}_{4}\right)_{2}$ and $\mathrm{P}_{2} \mathrm{O}_{5}$. The purification of air and oxygen was required to completely avoid carbonate and oxycarbonate phases in equilibrated samples.

\section{Determination of the Phase Diagram}

Isothermal phase relations in the system $\mathrm{CaO}-\mathrm{SrO}-\mathrm{PbO}-$ $\mathrm{O}_{2}$ at $1100 \mathrm{~K}$ were explored by equilibrating oxide mixtures representing 30 different compositions in air, pure oxygen, or evacuated ampoules, followed by quenching and phase identification. Precisely measured quantities of the component oxides were first thoroughly mixed using a vibratory mill with an agate container and balls and were subsequently compacted at $100 \mathrm{MPa}$ pressure in a steel die. Pellets containing more than 50 mol.\% $\mathrm{PbO}$ were contained in yttriastabilized zirconia crucibles, supported on sacrificial disks of the same composition. Pellets containing lower concentrations of $\mathrm{PbO}$ were contained in platinum crucibles.

The apparatus for equilibrating the samples in air or pure oxygen was similar to that described elsewhere. ${ }^{[2]}$ It was necessary to remove trace moisture from the gas phase to obtain the correct phase relations. The crucibles containing the sample pellets were suspended inside an alumina tube, which was placed in the even temperature zone of a vertical furnace. Samples were equilibrated for a total duration of $\sim 7$ days at $1100 \mathrm{~K}$. The samples were quenched, ground to 325 mesh, and repelletized twice during this period. All mixing and pelletizing operations were conducted in a dry box. Preliminary experiments indicated that the time for the attainment of equilibrium was $\sim 5$ days. In order to ensure the attainment of equilibrium, the samples were actually heat treated for a much longer duration. The temperature of the sample was measured by a $\mathrm{Pt} / \mathrm{Pt}-13 \% \mathrm{Rh}$ thermocouple, calibrated against the melting point of $\mathrm{Au}$. The flow rate of dry air or oxygen through the tube was set at $4 \mathrm{~mL} / \mathrm{s}$ using a mass flow controller. At the end of the equilibration period, the sample was quenched by releasing the suspension wire. The crucible containing the sample burned through a cellophane diaphragm on its descent and was collected in a flask containing chilled mercury. Rapid quenching and provision of an inert atmosphere in the quench chamber were required to suppress the oxidation of $\mathrm{PbO}$. Even with these precautions, small amounts of higher oxides of lead were detected by XRD in some of the samples. Under the experimental conditions of this study, $\mathrm{Pb}_{3} \mathrm{O}_{4}$ and the higher oxides are unstable. ${ }^{[11]}$ In an attempt to check the origin of these higher oxides, air in the alumina tube surrounding the sample was rapidly replaced by helium at the end of equilibration, and the sample was immediately dropped countercurrent to the gas flowing at $\sim 12 \mathrm{~mL} / \mathrm{s}$. Since some higher binary oxides of lead were detected in samples containing the liquid phase even with this procedure, it must be concluded that a significant amount of $\mathrm{Pb}^{4+}$ ions exist in the liquid.

Part of the quenched sample was mounted and polished for EDX and optical microscopy. A part of the sample was analyzed by XRD using either $\mathrm{Cu} K_{\alpha}$ or $\mathrm{Co} K_{\alpha}$ radiation. Mixed with the powder sample for XRD was metallic silicon, which acted as an internal standard so that accurate cell dimensions could be obtained by least-squares refinement of

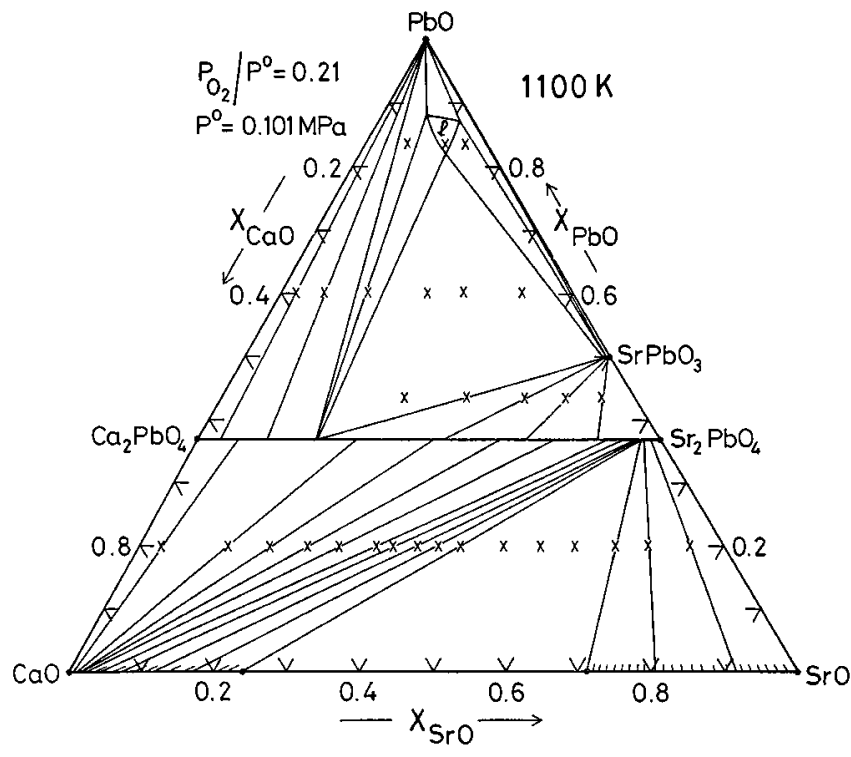

Fig. 3 Projection of phase relations in the quaternary system $\mathrm{CaO}$ $\mathrm{SrO}-\mathrm{PbO}-\mathrm{O}_{2}$ in air at $1100 \mathrm{~K}$ onto the ternary triangle $\mathrm{CaO}-\mathrm{SrO}-\mathrm{PbO}$

$d$ spacings. An EDX unit attached to a scanning electron microscope was used to confirm the results obtained by XRD and to determine the composition of coexisting phases. The beam size was $0.2 \mu \mathrm{m}$. Synthetic samples of $\mathrm{CaO}, \mathrm{Sr}_{2} \mathrm{PbO}_{4}$, and $\mathrm{SrPbO}_{3}$ were used as standards for EDX. Grain size larger than $10 \mu \mathrm{m}$ was used for good reproducibility with EDX.

The oxygen content of single-phase oxides containing lead was determined by hydrogen reduction at $1223 \mathrm{~K}$. The reduction produced $\mathrm{AO}(\mathrm{A}=\mathrm{Sr}, \mathrm{Ca})$ and metallic $\mathrm{Pb}$. From the mass change during reduction, measured by a microbalance, the oxygen content of the sample was evaluated.

\section{Results and Discussion}

\section{Phase Diagram}

Crosses in Fig. 3 show the initial compositions of the various samples examined in this study. For each composition, three samples were prepared using different starting mixtures. After 7 days equilibration at $1100 \mathrm{~K}$, the final phase composition was almost identical for all samples with the same average composition. An isothermal representation of phase relations in air at $1100 \mathrm{~K}$, composed from the results obtained in this study, is shown in Fig. 3. The diagram is not an isothermal section but rather a projection of equilibrium phase relations in the quaternary $\mathrm{CaO}-\mathrm{SrO}-\mathrm{PbO}-\mathrm{O}_{2}$ from the $\mathrm{O}_{2}$ apex onto the ternary section $\mathrm{CaO}-\mathrm{SrO}-\mathrm{PbO}$. Chemical analysis confirmed the formulas of ternary oxides and their solid solutions.

The monoxide solid solution with the rock-salt structure exhibits a miscibility gap. The solubility limits observed in this study are almost identical with those reported earlier. ${ }^{[8]}$ There is continuous solid solubility between $\mathrm{Ca}_{2} \mathrm{PbO}_{4}$ and $\mathrm{Sr}_{2} \mathrm{PbO}_{4}$ at $1100 \mathrm{~K}$. The single-phase region of this solid solution is a straight line connecting the stoichiometric end 
Table 1 Compositions of the monoxide solid solution $\left(\mathrm{Ca}_{1-x} \mathrm{Sr}_{x}\right) \mathrm{O}$ with rock-salt structure in equilibrium with $\left(\mathrm{Ca}_{1-y} \mathrm{Sr}_{y}\right)_{2} \mathrm{PbO}_{4}$ solid solution with orthorhombic structure at $1100 \mathrm{~K}$

\begin{tabular}{cc} 
Mole fraction of SrO & $\begin{array}{c}\text { Mole fraction of } \mathbf{S r}_{2} \mathbf{P b O}_{\mathbf{4}} \\
\boldsymbol{x}\end{array}$ \\
\hline 0.006 & 0.088 \\
0.013 & 0.344 \\
0.015 & 0.504 \\
0.018 & 0.653 \\
0.024 & 0.773 \\
0.046 & 0.889 \\
0.073 & 0.926 \\
0.121 & 0.948 \\
0.174 & 0.957 \\
0.240 & 0.961 \\
0.712 & 0.961 \\
0.805 & 0.966 \\
0.914 & 0.980 \\
\hline
\end{tabular}

members. Tie-lines connect the monoxide solid solution $\left(\mathrm{Ca}_{1-x} \mathrm{Sr}_{x}\right) \mathrm{O}$ with the solid solution $\left(\mathrm{Ca}_{1-y} \mathrm{Sr}_{y}\right)_{2} \mathrm{PbO}_{4}$ having the orthorhombic structure. The tie-lines are skewed toward the $\mathrm{Sr}_{2} \mathrm{PbO}_{4}$ corner. The tie-line compositions are summarized in Table 1. Attainment of equilibrium was checked by the conventional "tie-line rotation" technique. The relation between the compositions of the two solutions is shown graphically in Fig. 4. The monoxide solid solutions with $x=$ 0.24 and 0.71 , on either side of the miscibility gap, are in equilibrium with $\left(\mathrm{Ca}_{1-y} \mathrm{Sr}_{y}\right)_{2} \mathrm{PbO}_{4}$ with $y=0.96$. Wong- $\mathrm{Ng}$ et al. ${ }^{[17]}$ reported somewhat different results; they give $x=$ 0.11 and 0.83 as the boundaries of the monoxide solid solution and $y=0.95$ as the equilibrium composition of the orthorhombic phase. Almost identical tie-line compositions were obtained when equilibrations were conducted in pure oxygen, air, or evacuated quartz ampoules. Thus, the tieline composition between the two solid solutions is not sensitive to oxygen partial pressure. However, samples prepared from $\mathrm{CaO}, \mathrm{SrO}, \mathrm{PbO}$, and $\left(\mathrm{Ca}_{1-y} \mathrm{Sr}_{y}\right)_{2} \mathrm{PbO}_{4}$ as starting materials, when heat treated in evacuated quartz ampoules, revealed a three-phase region involving $\mathrm{PbO}, \mathrm{Ca}_{1-x} \mathrm{Sr}_{x} \mathrm{O}$, and $\left(\mathrm{Ca}_{1-y} \mathrm{Sr}_{y}\right)_{2} \mathrm{PbO}_{4}$, with values of $x$ and $y$ that fall on the curve in Fig. 4. This three-phase field was not observed in identical samples equilibrated in air or oxygen.

The substitution of $\mathrm{Ca}^{2+}$ for $\mathrm{Sr}^{2+}$ occurs only to a limited extent ( $\sim 2 \mathrm{~mol} . \%)$ in $\mathrm{SrPbO}_{3}$, which also has an orthorhombic structure, space group Pbmn (53). The $\left(\mathrm{Ca}_{1-z} \mathrm{Sr}_{z}\right) \mathrm{PbO}_{3}$ solid solution can probably be stabilized at low temperatures and high pressures of oxygen. The terminal solid solution $\left(\mathrm{Ca}_{1-z} \mathrm{Sr}_{z}\right) \mathrm{PbO}_{3}$ coexists with $\left(\mathrm{Ca}_{1-y} \mathrm{Sr}_{y}\right)_{2} \mathrm{PbO}_{4}$ for $y \geq 0.255$ in air at $1100 \mathrm{~K}$. In pure oxygen at ambient pressure, the coexistence between the two solid solutions extends up to $y$ $\geq 0.12$. The solid solutions $\left(\mathrm{Ca}_{1-y} \mathrm{Sr}_{y}\right)_{2} \mathrm{PbO}_{4}$ with $y \leq 0.255$ in air and $y \leq 0.12$ in pure oxygen are in equilibrium with pure solid $\mathrm{PbO}$. Kitaguchi et al. ${ }^{[16]}$ reported a three-phase region involving $\mathrm{PbO}, \mathrm{Ca}_{2} \mathrm{PbO}_{4}$, and $\mathrm{SrPbO}_{3}$ in air at $\sim 1123$ $\mathrm{K}$. The results of this study clearly show that pure $\mathrm{Ca}_{2} \mathrm{PbO}_{4}$ is not involved in this three-phase equilibrium; rather, a solid

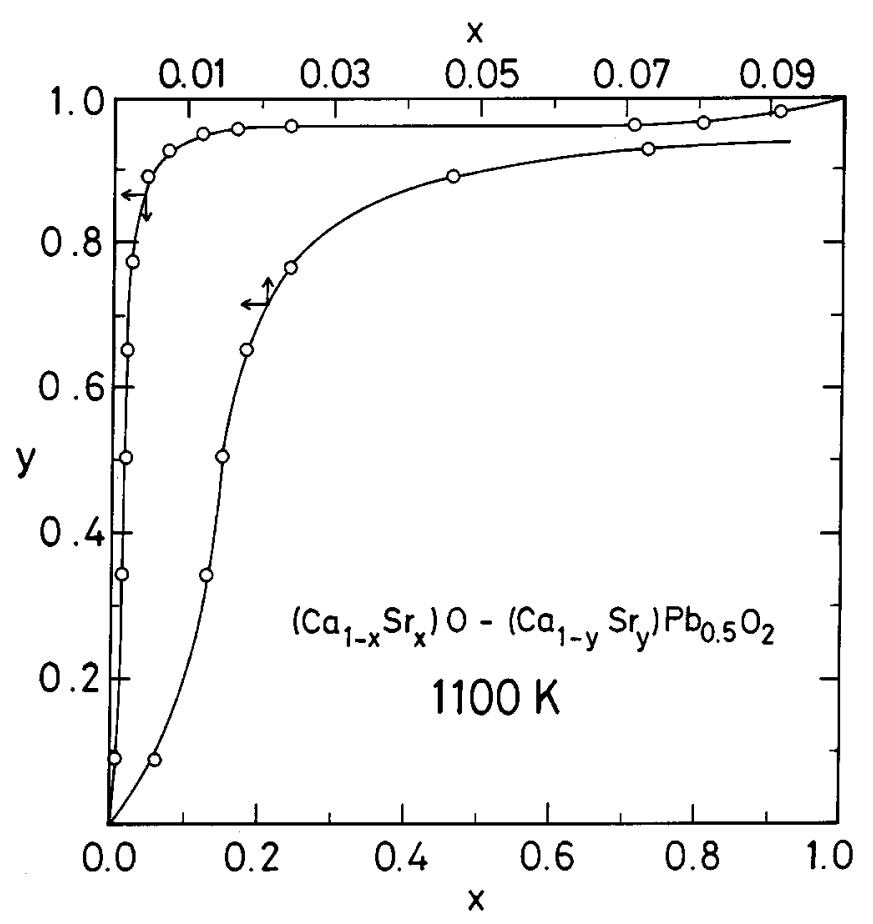

Fig. 4 Relation between compositions of coexisting phases belonging to the solid solutions with rock-salt and orthorhombic structures at $1100 \mathrm{~K}$. The lower curve shows the low concentration data with an expanded scale

solution $\left(\mathrm{Ca}_{1-y} \mathrm{Sr}_{y}\right)_{2} \mathrm{PbO}_{4}$. The composition of the solid solution varies with oxygen partial pressure. In pure oxygen at ambient pressure, the value of $y$ is 0.12 . In air, the value of $y=0.255$ found in this study at $1100 \mathrm{~K}$ is in fair agreement with $y=0.2$ reported by Wong-Ng et al. ${ }^{[17]}$ at $1105 \mathrm{~K}$.

A small triangular liquid-phase region exists near the $\mathrm{PbO}$ corner, surrounded by three two-phase fields $\left(\left(\mathrm{Ca}_{1-z} \mathrm{Sr}_{z}\right) \mathrm{PbO}_{3}\right.$ + liquid, $\left(\mathrm{Ca}_{1-y} \mathrm{Sr}_{y}\right)_{2} \mathrm{PbO}_{4}+$ liquid, and $\mathrm{PbO}(\mathrm{s})+$ liquid $)$. Each corner of the approximately triangular liquid-phase region is associated with a three-phase field. Chemical analysis indicates the presence of some $\mathrm{Pb}^{4+}$ ions $(\sim 10 \%$ under pure oxygen) in the liquid, although its concentration could not be determined accurately since the higher oxides of lead tend to segregate during quench. The liquid phase has not been shown in diagrams published earlier. ${ }^{[16,17]}$

Displayed in Fig. 5 is a three-dimensional diagram for the quaternary system $\mathrm{CaO}-\mathrm{SrO}-\mathrm{PbO}-\mathrm{O}_{2}$ in pure oxygen at 1100 $\mathrm{K}$. In order to visualize clearly the projection of the phase relations in the quaternary diagram onto the base triangle, the small liquid-phase region is omitted for convenience. The presence of three-phase regions such as $\mathrm{PbO}+\left(\mathrm{Ca}_{1-x} \mathrm{Sr}_{x}\right) \mathrm{O}$ $+\left(\mathrm{Ca}_{1-\gamma} \mathrm{Sr}_{y}\right)_{2} \mathrm{PbO}_{4}$ that occur at reduced partial pressures of oxygen can easily be observed in this diagram.

\section{Mixing Properties of the Solid Solution $\left(\mathrm{Ca}_{1-y} \mathrm{Sr}_{y}\right)_{2} \mathrm{PbO}_{4}$}

The formation of the solid solution between $\mathrm{Ca}_{2} \mathrm{PbO}_{4}$ and $\mathrm{Sr}_{2} \mathrm{PbO}_{4}$ involves the mixing of two $\mathrm{Ca}^{2+}$ and $\mathrm{Sr}^{2+}$ ions per formula unit. The other ions are common and they occupy crystallographically identifiable sites. It is more appropriate, therefore, to express activities and mixing properties in terms 
of one mole of the mixing species. Following Kerric and Darken, ${ }^{[18]}$ the composition variables are chosen as $\mathrm{CaPb}_{0.5} \mathrm{O}_{2}$ and $\mathrm{SrPb}_{0.5} \mathrm{O}_{2}$. With this choice of composition variables, the logarithm of the activity coefficients will always have a finite value and will not go to minus infinity as concentration approaches zero. Activities in the two scales are related: $a_{\mathrm{Ca}_{2} \mathrm{PbO}_{4}}=a_{\mathrm{CaPb}_{0.5} \mathrm{O}_{2}}^{2} ; a_{\mathrm{Sr}_{2} \mathrm{PbO}_{4}}=a_{\mathrm{SrPb}_{0.5} \mathrm{O}_{2}}^{2}$.

Activity coefficients of components of the solid solution $\left(\mathrm{Ca}_{1-y} \mathrm{Sr}_{y}\right) \mathrm{Pb}_{0.5} \mathrm{O}_{2}$ can be derived from the compositions of tie-lines between the solid solution and the monoxide phase $\left(\mathrm{Ca}_{1-x} \mathrm{Sr}_{x}\right) \mathrm{O}$. Each tie-line is defined by the intercrystalline ion-exchange reaction:

$\mathrm{CaPb}_{0.5} \mathrm{O}_{2}+\mathrm{SrO} \rightarrow \mathrm{CaO}+\mathrm{SrPb}_{0.5} \mathrm{O}_{2}$

for which

$K_{1}=\exp \left(-\Delta G_{1}^{o} / \mathrm{R} T\right)=\frac{a_{\mathrm{SrPb}_{0.5} \mathrm{O}_{2}} \cdot a_{\mathrm{CaO}}}{a_{\mathrm{CaPb}_{0.5} \mathrm{O}_{2}} \cdot a_{\mathrm{SrO}}}$

where $\mathrm{K}_{1}$ and $\Delta G_{1}^{o}$ are the equilibrium constant and standard Gibbs energy change for Reaction 1. Expressing each activity as a product of activity coefficient and mole fraction, and rearranging;

$\frac{\gamma_{\mathrm{SrPb}_{0.5} \mathrm{O}_{2}}}{\gamma_{\mathrm{CaPb}_{0.5} \mathrm{O}_{2}}}=K_{1} \frac{(1-y)}{y} \cdot \frac{x}{(1-x)} \cdot \frac{\gamma_{\mathrm{SrO}}}{\gamma_{\mathrm{CaO}}}$

Following the modified Gibbs-Duhem integration technique of Jacob and Jeffes, ${ }^{[19]}$

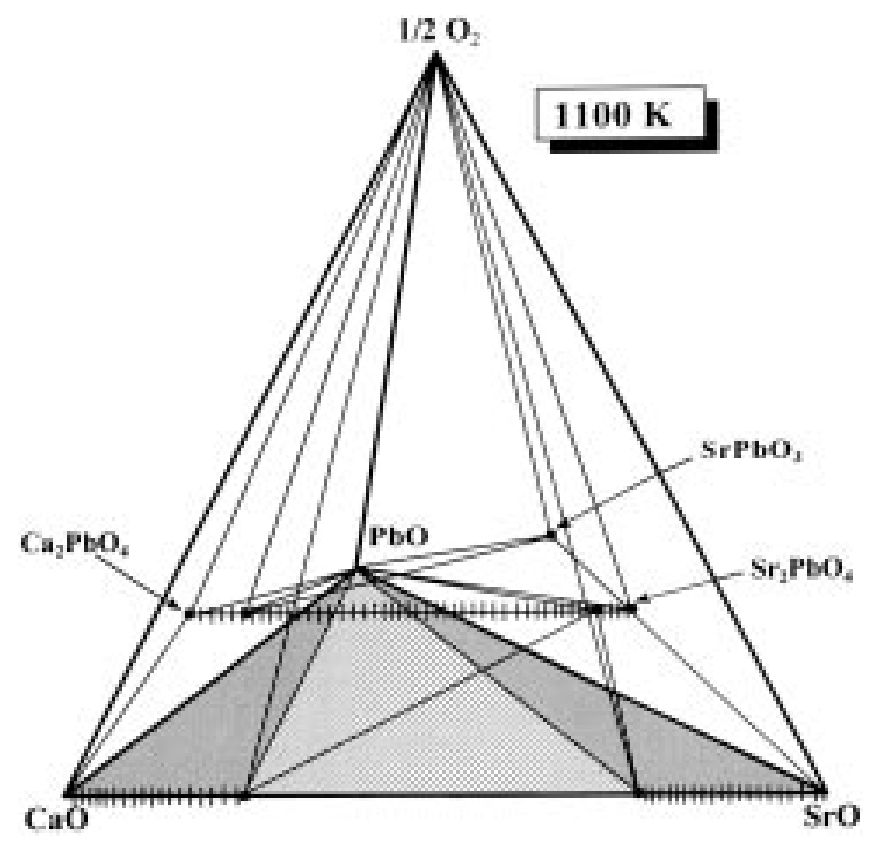

Fig. 5 Phase relations in the quaternary system $\mathrm{CaO}-\mathrm{SrO}-\mathrm{PbO}-\mathrm{O}_{2}$ in oxygen at $1100 \mathrm{~K}$. Presence of the liquid phase near the $\mathrm{PbO}$ corner is omitted for clarity

$$
\begin{aligned}
\ln \gamma_{\mathrm{SrPb}_{0.5} \mathrm{O}_{2}} & =\int_{y=1}^{y}(1-y) d \ln \left(\gamma_{\mathrm{SrPb}_{0.5} \mathrm{O}_{2}} / \gamma_{\mathrm{CaPb}_{0.5} \mathrm{O}_{2}}\right) \\
& =\int_{y=1}^{y}(1-y) d \ln \left\{\frac{x(1-y) \gamma_{\mathrm{SrO}}}{y(1-x) \gamma_{\mathrm{CaO}}}\right\}
\end{aligned}
$$

For the solution $\mathrm{Ca}_{1-x} \mathrm{Sr}_{x} \mathrm{O}$, the partial excess Gibbs energies have been evaluated recently: ${ }^{[8]}$

$$
\begin{aligned}
\Delta G_{\mathrm{CaO}}^{E} & =\mathrm{R} T \ln \gamma_{\mathrm{CaO}}=x^{2}(29,165-6.3 T) \\
& -x^{3}(4,250-0.96 T) \quad \mathrm{J} / \mathrm{mol} \\
\Delta G_{\mathrm{SrO}}^{E} & =\mathrm{R} T \ln \gamma_{\mathrm{SrO}} \\
& =(1-x)^{2}(22,790-4.86 T) \\
& +(1-x)^{3}(4,250-0.96 T) \quad \mathrm{J} / \mathrm{mol} .
\end{aligned}
$$

The integration plot shown in Fig. 6 can be derived from Eq 4 and the above data. A second-order polynomial gives a good fit to experimental data. The value of $\ln \gamma_{\mathrm{SrPb}_{0.5} \mathrm{O}_{2}}$ is obtained as the area under the curve between the limits of integration. Since $\mathrm{K}_{1}$ is a constant, its value does not affect the area under the curve and the evaluation of the mixing properties. The activity coefficient of $\mathrm{SrPb}_{0.5} \mathrm{O}_{2}$ obtained by integration can be adequately represented by the equation

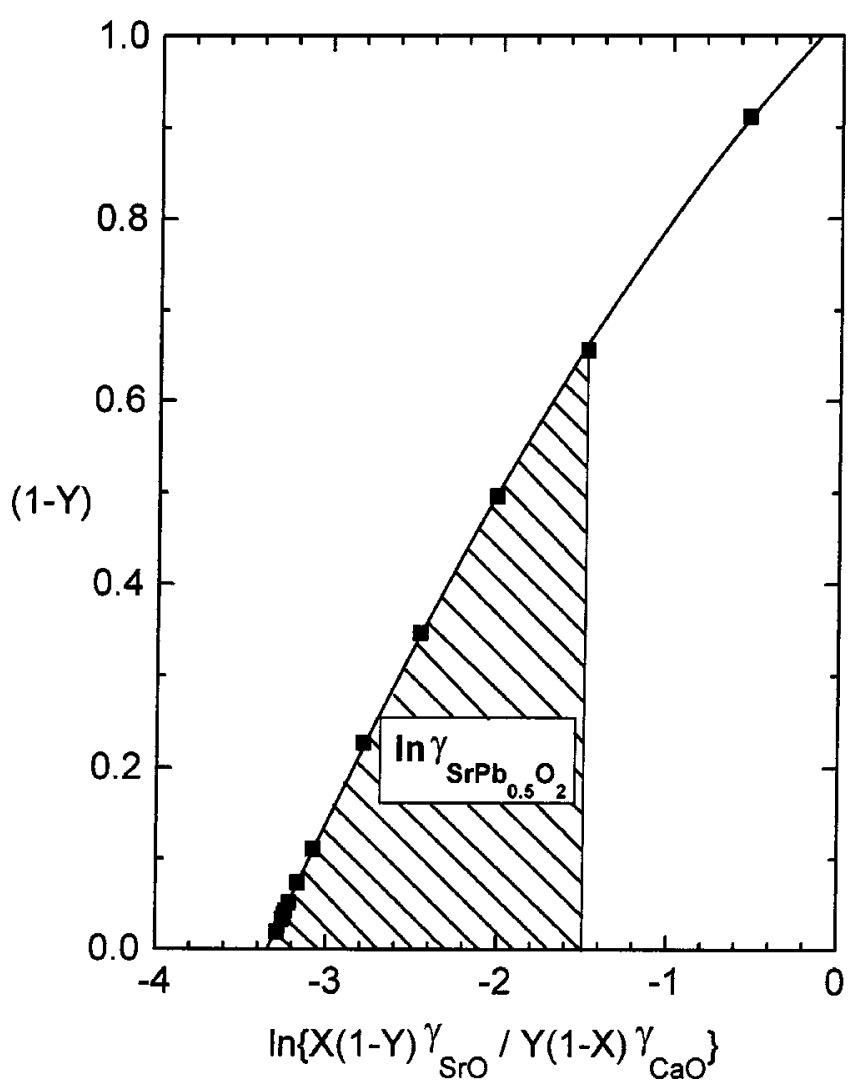

Fig. 6 Integration plot for deriving activity coefficients from tieline data 
$\ln \gamma_{\mathrm{SrPb}_{0.5} \mathrm{O}_{2}}=(1-y)^{2}(1.732-0.6451 y)$

based on the subregular solution model. ${ }^{[20]}$ Similarly, the activity coefficient of $\mathrm{CaPb}_{0.5} \mathrm{O}_{2}$ is evaluated as a function of composition from the area above the curve in Fig. 6:

$\ln \gamma_{\mathrm{CaPb}_{0.5} \mathrm{O}_{2}}=\int_{y=0}^{y} y d \ln \left\{\frac{y(1-x) \gamma_{\mathrm{CaO}}}{x(1-y) \gamma_{\mathrm{SrO}}}\right\}$

Alternatively, the activity coefficient of $\mathrm{CaPb}_{0.5} \mathrm{O}_{2}$ can also be obtained by integrating Eq 7 using the Gibbs-Duhem relationship. The activity coefficient of $\mathrm{CaPb}_{0.5} \mathrm{O}_{2}$ is represented by the equation

$\ln \gamma_{\mathrm{CaPb}_{0.5} \mathrm{O}_{2}}=y^{2}(2.054-0.6451 y)$

The activities of the components of the solid solution, calculated from Eq 7 and 9, exhibit large positive deviations from Raoult's law at $1100 \mathrm{~K}$, as shown in Fig. 7. Combination of the two activity coefficients yields the excess Gibbs energy of mixing for the binary system $\mathrm{CaPb}_{0.5} \mathrm{O}_{2}-\mathrm{SrPb}_{0.5} \mathrm{O}_{2}$ at $1100 \mathrm{~K}$ :

$\Delta G^{E}=y(1-y)(15,840-2,950 y) \mathrm{J} / \mathrm{mol}$

The excess Gibbs energy of mixing is asymmetric. If the entropy of mixing is assumed ideal, then the excess Gibbs energy is equal to the enthalpy of mixing. The introduction

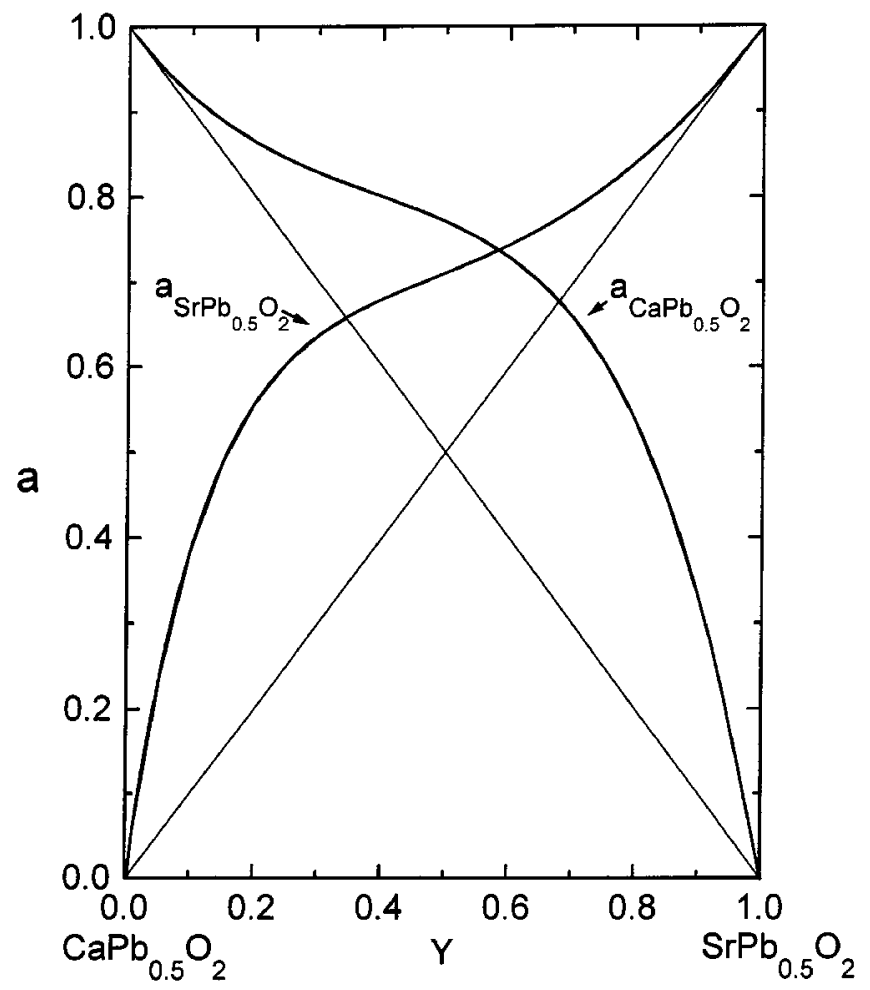

Fig. 7 Variation of activities with composition at $1100 \mathrm{~K}$ for components in the solid solution $\left(\mathrm{Ca}_{1-y} \mathrm{Sr}_{y}\right) \mathrm{Pb}_{0.5} \mathrm{O}_{2}$ having orthorhombic structure. The activities were derived from tie-line data using the modified Gibbs-Duhem integration technique of Jacob and Jeffes ${ }^{[19]}$ of $\mathrm{Sr}^{2+}$ ions into the lattice of $\mathrm{CaPb}_{0.5} \mathrm{O}_{2}$ is more exothermic than the substitution of $\mathrm{Ca}^{2+}$ for the larger $\mathrm{Sr}^{2+}$ in $\mathrm{SrPb}_{0.5} \mathrm{O}_{2}$. The excess Gibbs energy of mixing for $\left(\mathrm{Ca}_{1-y} \mathrm{Sr}_{y}\right) \mathrm{Pb}_{0.5} \mathrm{O}_{2}$ is less exothermic $\left(\Delta G^{E}=3590 \mathrm{~J} / \mathrm{mol}\right.$ at $\left.y=0.5\right)$ than for the $\left(\mathrm{Ca}_{1-x} \mathrm{Sr}_{x}\right) \mathrm{O}$ solid solution $\left(\Delta G^{E}=4960 \mathrm{~J} / \mathrm{mol}\right.$ at $\left.x=0.5\right)$. Computing values of the equilibrium constant or Gibbs energy change for Reaction 1 from each tie-line, one can check the accuracy of the measured compositions. The activity coefficients for the solid solutions with rock-salt and orthorhombic structures previously given are used in the computation. The values obtained from $\mathrm{Eq} 2$ are $\mathrm{K}_{1}=6.82$ $( \pm 0.06)$ and, hence, $\Delta G_{1}^{o}=-17,555( \pm 80) \mathrm{J} / \mathrm{mol}$ at 1100 $\mathrm{K}$. The error limits correspond to twice the standard deviation. The value for the standard Gibbs energy change is in excellent agreement with the value of $\Delta G_{1}^{o}=-17,592$ $( \pm 195) \mathrm{J} / \mathrm{mol}$ obtained from recent electromotive force measurements. ${ }^{[11,14]}$ Thus, accurate phase diagram data can generate thermodynamic properties with a precision comparable to direct measurements.

\section{Exsolution of the Solid Solution with Orthorhombic Structure}

Since activities in the system $\mathrm{CaPb}_{0.5} \mathrm{O}_{2}-\mathrm{SrPb}_{0.5} \mathrm{O}_{2}$ exhibit large positive deviations at $1100 \mathrm{~K}$, a miscibility gap is expected to form at lower temperatures. Assuming that the excess Gibbs energy of mixing is independent of temperature, both the binodal and spinodal curves for the pseudobinary system can be computed. At constant temperature, the activity of each component is constant across the miscibility gap (bimodal curve): $\Delta G_{\mathrm{CaPb}_{0.5} \mathrm{O}_{2}}\left(y_{1}\right)=\Delta G_{\mathrm{CaPb}_{0.5} \mathrm{O}_{2}}\left(y_{2}\right)$, and $\Delta G_{\mathrm{SrPb}_{0.5} \mathrm{O}_{2}}\left(y_{1}\right)=\Delta G_{\mathrm{SrPb}_{0.5} \mathrm{O}_{2}}\left(y_{2}\right)$. The locus of chemical spinodal points is defined by $\left(\partial^{2} \Delta G / \partial y^{2}\right)=0$. The results are shown in Fig. 8. The miscibility gap is asymmetric, characterized by a critical temperature of $884( \pm 5) \mathrm{K}$ and critical composition $y=0.43( \pm 0.02)$.

\section{Conclusions}

In the system $\mathrm{CaO}-\mathrm{SrO}-\mathrm{PbO}-\mathrm{O}_{2}$, there exist compounds and solid solutions, $\left(\mathrm{Ca}_{1-y} \mathrm{Sr}_{y}\right)_{2} \mathrm{PbO}_{4}(1 \geq y \geq 0)$ and $\left(\mathrm{Ca}_{1-z} \mathrm{Sr}_{z}\right) \mathrm{PbO}_{3}(0.02 \geq z \geq 0)$, that contain lead in the tetravalent state. Surprisingly, there is no ternary solid phase containing lead in divalent state, even though $\mathrm{PbO}$ is the only binary oxide stable at high temperature and ambient pressure. This is in line with the general trend of stabilization of higher oxidation states of elements of Groups IV and V in their ternary compounds with basic oxides such as $\mathrm{CaO}$, $\mathrm{SrO}$, and $\mathrm{BaO} ;{ }^{[10-14]}$ thus, one concludes that the stronger the base, the greater is the stabilization. The liquid phase near the $\mathrm{PbO}$ corner contains primarily $\mathrm{Pb}^{2+}$ ions with a significant amount of $\mathrm{Pb}^{4+}$.

Equilibria involving the quaternary phases in air or oxygen can be projected from the oxygen apex onto the ternary triangle $\mathrm{CaO}-\mathrm{SrO}-\mathrm{PbO}$. However, the projection will not reveal phase relations that occur in the quaternary system at lower oxygen partial pressures. A simplified quaternary diagram is presented, which helps to visualize the different phase fields. 


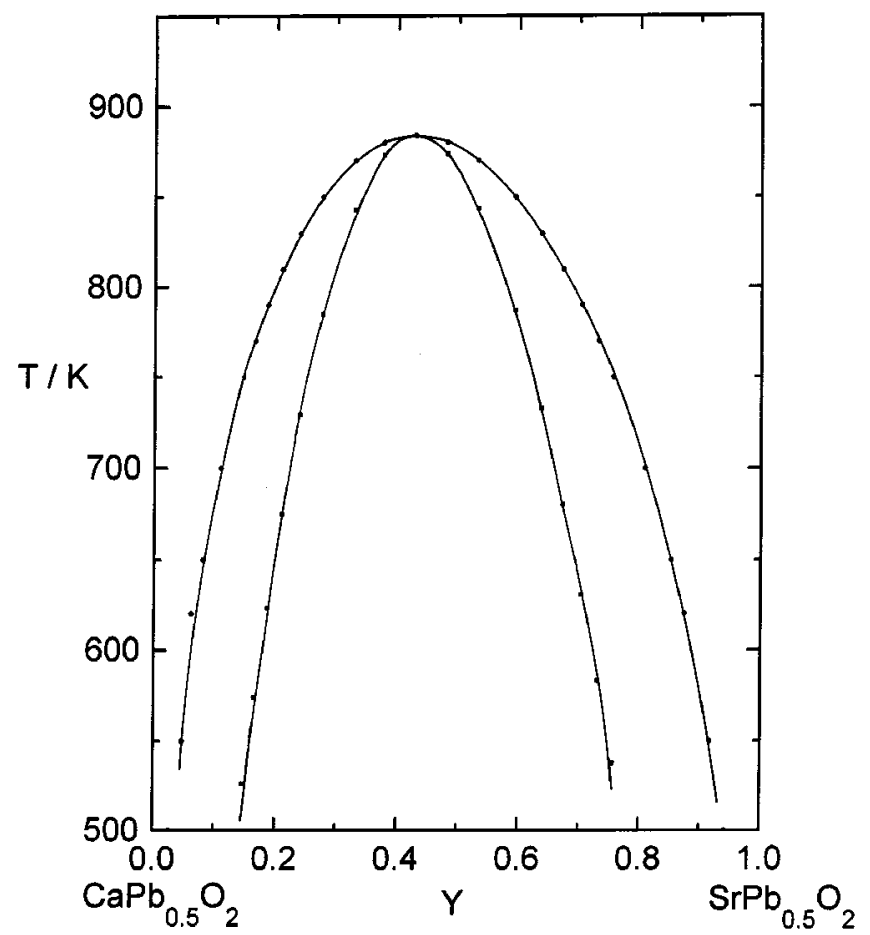

Fig. 8 Loci of binodal and chemical spinodal points for the solid solution $\left(\mathrm{Ca}_{1-y} \mathrm{Sr}_{y}\right) \mathrm{Pb}_{0.5} \mathrm{O}_{2}$, computed from thermodynamic data obtained in this study

Thermodynamic mixing properties of the solid solution $\left(\mathrm{Ca}_{1-y} \mathrm{Sr}_{y}\right) \mathrm{Pb}_{0.5} \mathrm{O}_{2}$ were derived from quantitative measurement of tie-line compositions using the method of Jacob and Jeffes. ${ }^{[19]}$ The tie-lines connecting the monoxide solid solution $\left(\mathrm{Ca}_{1-x} \mathrm{Sr}_{x}\right) \mathrm{O}$ with $\left(\mathrm{Ca}_{1-y} \mathrm{Sr}_{y}\right) \mathrm{Pb}_{0.5} \mathrm{O}_{2}$ are skewed toward the $\mathrm{SrPb}_{0.5} \mathrm{O}_{2}$ corner. The miscibility gap in the monoxide solid solution reported earlier ${ }^{[8]}$ was confirmed. The formula for the solid solution is written such that there is only one mole of the mixing species. The subregular model can represent the excess Gibbs energy of mixing of the solid solution with orthorhombic structure at $1100 \mathrm{~K}$ :

$$
\Delta G^{E}=(1-y) y[15,840-2950 y] \mathrm{J} / \mathrm{mol}
$$

The thermodynamic properties of the monoxide solid solution were evaluated earlier. ${ }^{[8]}$ The accuracy of measurements was independently checked by computing a value for the Gibbs energy change for the exchange reaction from each tie-line.
The thermodynamic data suggest the occurrence of an asymmetric miscibility gap in the pseudobinary $\mathrm{Ca}_{2} \mathrm{PbO}_{4}-$ $\mathrm{Sr}_{2} \mathrm{PbO}_{4}$ with a critical parameter $\mathrm{T}_{\mathrm{C}}=884( \pm 5) \mathrm{K}$ and $y_{C}=0.43$.

\section{Acknowledgment}

One of the authors (KPJ) thanks the Council of Scientific and Industrial Research (CSIR), New Delhi, India, for a Senior Research Fellowship (SRF).

\section{References}

1. M. Zaharescu, A. Braileanu, and D. Crisaw: J. Therm. Anal., 1993, vol. 40, pp. 321-27.

2. K.T. Jacob and T. Mathews: J. Mater. Chem., 1991, vol. 1, pp. 545-49.

3. K.T. Jacob and T. Mathews: J. Am. Ceram. Soc., 1992, vol. 75, pp. 3225-32.

4. T. Mathews, J.P. Hajra, and K.T. Jacob: Chem. Mater., 1993, vol. 5, pp. 1669-75.

5. K.T. Jacob, T. Mathews, and J.P. Hajra: High Temp. Mater. Processing, 1993, vol. 12, pp. 251-58.

6. K.T. Jacob and Y. Waseda: J. Phase Equilibria, 1994, vol. 15, pp. 401-05.

7. K.T. Jacob and V. Varghese: J. Mater. Chem., 1995, vol. 5, pp. 1059-62.

8. K.T. Jacob and Y. Waseda: J. Am. Ceram. Soc., 1998, vol. 81, pp. 1065-68.

9. K.T. Jacob, P.M. Raj, and Y. Waseda: J. Phase Equilibria, 1995, vol. 16, pp. 113-20.

10. K.T. Jacob and K.P. Jayadevan: Mater. Trans., JIM, 1997, vol. 38, pp. 427-36.

11. K.T. Jacob and K.P. Jayadevan: J. Mater. Chem., 1997, vol. 7, pp. 2407-13.

12. K.T. Jacob and K.P. Jayadevan: J. Mater. Res., 1998, vol. 13 (7), pp. 1905-18.

13. K.T. Jacob and K.P. Jayadevan: Mater. Sci. Eng. B, 1998, vol. B52, pp. 134-44.

14. K.T. Jacob and K.P. Jayadevan: Chem. Mater, 2000, vol. 12 (6), pp. 1779-86.

15. M. Xu, D.K. Finnemore, and W. Gao: J. Mater. Res., 1996, vol. 11, pp. 3045-47.

16. H. Kitaguchi, J. Takoda, K. Oda, and Y. Miura: J. Mater. Res., 1990, vol. 5, pp. 1397-1402.

17. W. Wong-Ng, F. Jiang, and L.P. Cook: Physica C, 1996, vol. 272, pp. 87-93.

18. D.M. Kerric and L.S. Darken: Geochim. Cosmochim. Acta, 1975, vol. 39, pp. 1431-38.

19. K.T. Jacob and J.H.E. Jeffes: High Temp.-High Pressure, 1972, vol. 4, pp. 177-82.

20. H.K. Hardy: Acta Metall., 1953, vol. 1, pp. 202-09. 